\title{
Leitura de gênero sobre os estudos de segurança internacional
}

\author{
Gender-based interpretation of international security studies
}

\section{Claudia Santos ${ }^{1}$}

\begin{abstract}
RESUMO
O que esta pesquisa se propõe a apresentar é uma leitura de gênero dos Estudos de Segurança Internacional a partir dos estudos feministas de segurança que fazem parte das Teorias contemporâneas de Segurança Internacional, no qual se reivindica uma expansão do objeto de referência para que se incluam mulheres. A hipótese deste trabalho é de que apesar do crescente esforço teórico para a inclusão de mulheres nos Estudos de Segurança Internacional e da ONU por meio das suas resoluções, percebe-se que na realidade as instituições militares continuam apresentando uma postura pouco democrática quanto à inserção de mulheres e em certa medida essencialista, principalmente com relação aos conflitos e o papel da mulher, que é excluída das posições de combate e colocada em posições relacionadas às missões de paz.
\end{abstract}

Palavras-chave: Segurança Internacional, Feminismo, Instituições Militares.

\begin{abstract}
The present research presents a gender-based interpretation of International Security Studies from the perspective of feminist security studies, a branch of the contemporary Theories on International Security that advocates for the expansion of the study object toward the inclusion of women. I present the hypothesis that despite growing theoretical efforts to include women in International Security Studies and through UN resolutions, in reality military institutions continue to have an undemocratic - and to some extent essentialist - stance on the inclusion of women, especially with regard to conflicts and the role of women, who are excluded from combat roles and placed in positions related to peacekeeping missions.
\end{abstract}

Keywords: International Security, Feminism, Military Institutions.

\section{INTRODUÇÃO}

A nova ordem mundial que se manifesta no Pós-Guerra Fria permitiu aos teóricos das Relações Internacionais atentarem para outras questões além do Estado como, por exemplo, para a identidade, o interesse e a experiência no que tange a questão da política mundial. Dentre as mudanças ocorridas neste período destaca-se por conta do objeto de estudo, o conceito de segurança, que passa de uma visão positivista e tradicional para uma discussão mais abrangente do conceito. 0 desafio desta nova

\footnotetext{
${ }^{1}$ Graduada em Relações Internacionais pelo Centro Universitário Internacional - UNINTER, graduanda em Ciências Sociais pela Universidade Federal do Paraná e mestranda em Ciência Política pela Universidade Federal do Paraná, Curitiba, Brasil.
}

Conjuntura Global, Vol. 4, n. 2, maio/ago., 2015, p. 171-184. 
ordem instaurada no Pós-Guerra Fria² é senão a de "enquadrar novos itens na agenda política global" (COSTA, 2009, p. 205).

Deste modo, a segurança passa a tratar de outros aspectos para além da esfera militar, o que se mostra no campo das Relações Internacionais como uma nova forma de conhecimento científico. A segurança diz respeito ao que se trata nas Relações Internacionais como alta política ${ }^{3}$, mas com as mudanças que ocorreram acerca do conceito do que é segurança, Buzan (apud Costa, 2009, p. 206) relata que é necessário levar em consideração a subjetividade da segurança, o que eleva o conceito de segurança a um âmbito muito mais amplo e abstrato do que o abordado por clivagens clássicas positivistas.

A abordagem do feminismo ${ }^{4}$ dentro das Relações Internacionais constitui um aparato teórico dentro das ciências humanas como um todo designada pela "integração inovadora entre consciência intelectual analítica de uma categoria empírica - a mulher com a consecução de uma longa jornada de atividade política, que visava se referir a uma declarada necessidade de transformar intensamente a concepção do papel histórico desse objeto e sujeito de estudos" (COSTA, 2009, p. 207).

Segundo Costa (2009), o feminismo nas questões de segurança tem seu início, a partir dos anos 80 onde emergem novas concepções sobre segurança internacional, por conta dos conflitos menos constantes e o surgimento de novas ameaças. Dentro do aspecto da segurança, a teoria feminista busca estruturar "seus trabalhos sobre a problemática da segurança a partir da crítica ao estadocentrismo e à dimensão militar das concepções tradicionais" (COSTA, 2009, p. 222). Segundo D’ Araújo (2004):

\footnotetext{
A incorporação de mulheres [...] às Forças Armadas só pode ser devidamente considerada quando as sociedades estabelecem para si que, liberdade de escolha e direitos iguais para todos, são parte inviolável da soberania individual, ou seja, quando os princípios de igualdade e democracia se tornarem a gramática da política (D’ARAÚJO, 2004).
}

\footnotetext{
2 O chamado "exército pós-moderno" tem como principais mudanças a flexibilização e a maior inclusão social. Esta organização militar pós-moderna que ocorre do Pós-Guerra Fria denota que apenas a diminuição de guerras é que justificaria a entrada das mulheres nas forças armadas.

${ }^{3}$ A denominação de High Politics e Low Politics faz referência à questão do que se considera como sistêmico e o que se considera como doméstico nos Estados. Dentro das High Politics está presente a segurança e das Low Politcs são responsáveis pelo bem-estar, por exemplo.

${ }^{4} \mathrm{O}$ feminismo se incorpora no chamando terceiro debate das Relações Internacionais, no qual as novas teorias possuem um teor crítico, de reflexão e insatisfação quanto às teorias até então existentes (positivistas) que ignoram o surgimento de mudanças no âmbito da política internacional.
} 
Para Buzan,\& Hansen (2012), nos estudos feministas de segurança, se destacam, especificamente, duas autoras Tickner e Cynthia Enloe. Segundo Tickner o feminismo adota uma análise multidimensional e multinível comprometida com “"visões emancipatórias de segurança" que procuram "compreender como a segurança dos indivíduos e dos grupos é comprometida pela violência, tanto física quanto estrutural, em todos os níveis"” (BUZAN \& HANSEN, 2012, p. 316). Sua abordagem geralmente é de baixo para cima e dão muito valor às experiências, demostrando que as vidas das mulheres são importantes. 0 feminismo traz à tona os sujeitos marginalizados por conceitos estadocentricos de segurança, como por exemplo, vítimas de estupro em guerras.

As pesquisadoras, Enloe e Tickner, também tratavam dos estereótipos de segurança, de protegido e protetor, e da construção que colocava os homens na linha de fogo e as mulheres em casa. Segundo esta perspectiva, os "problemas de segurança femininos eram privatizados, marginalizados ou, inclusive, silenciados, além disso, suas mortes eram contadas de modo diferente das dos homens militares" (BUZAN \& HANSEN, 2012, p.320).

Os autores Buzan,\& Hansen (2012) denotam também a existência do feminismo da diversidade e o feminismo pós-estruturalista. 0 feminismo da diversidade compreende a identidade não só por gênero, mas também por etnia e classe, já a análise feminista pós-estruturalista tem como objetivo "explorar e criticar o modo que as construções do sujeito condicionam a maneira como "as mulheres" podem aparecer" (BUZAN \& HANSEN, 2012, p.318). Segundo os autores, o feminismo pode adotar uma metodologia quantitativa, por exemplo, usar o gênero como variável explicativa de atitudes públicas para políticas de segurança. Apesar das diversas vertentes do feminismo, todas concordam acerca da busca pela equidade e veem o patriarcalismo como parte primordial que permeia todas as instituições, sendo assim suas críticas a abordagem tradicional do realismo tem contribuído para alterar paradigmas de segurança.

Para Tadjbakhsh (1965) o feminismo desafia a doutrina realista do Estado, no qual a figura central e ator principal é o "homem soberano" que é o símbolo do poder, o feminismo desta forma culpa o realismo por endossar um entendimento "masculinista" do mundo e de status do homem. Neste sistema é o "homem soberano" quem faz as escolhas racionais e legitima a violência, tornando desta forma as mulheres excluídas e 
controladas diretas, através da violência física, ou indiretamente, pelas concepções e ideologias que endossam papeis diferentes. 0 feminismo tem desafiado a visão do militarismo como defensor do interesse nacional, e afirma que a segurança do Estado também deve envolver estratégias não militares de negociação. Sendo assim, "Feminist geopolitics is not an alternative theory of geopolitics, but an approach to global issues with feminist politics in mind5" (Tadjbakhsh, 1965).

Sendo assim, feministas buscam uma aliança entre os movimentos das mulheres e outras forças excluídas. Sendo que elas se opõem à militarização e a veem como um aspecto de masculinidade. Além disso, as feministas acreditam que a concepção de segurança humana precisa ser generalizada, porque mesmo dentro de um quadro radical como "segurança das pessoas", é o homem que consegue os privilégios e os papeis especiais torando as necessidades das mulheres assumidas por agendas masculinas.

\section{0 gênero nas questões de Segurança da ONU}

De acordo com a perspectiva das Organizações Internacionais sobre mulher e conflito $^{6}$ é que "A igualdade de gênero, traduzida no "empowerment" feminino, é considerada, atualmente, condição sine qua non para a construção da paz" (IZZO, 2009, p. 191). Desde a sua primeira conferência sobre as mulheres em 1975 denominada “Declaração sobre a Igualdade das Mulheres e sua Contribuição para o Desenvolvimento e a Paz", a ONU relaciona mulher e paz. Aprovada no dia 31 de outubro do ano de 2000 pelo Conselho de segurança da ONU, a resolução 1325 diz respeito à questão da Paz, Mulheres e Segurança e tem como objetivo servir como instrumento fundamental de política para a proteção aos

[...] direitos das mulheres e meninas durante o conflito armado, combater a impunidade em crimes de gênero, promover a igualdade de gênero em operações de manutenção de paz, e aumentar a participação das mulheres nas atividades de pacificação, antes, durante e depois do conflito armado (FRITZ, 2010, p. 341).

\footnotetext{
5 Tradução - "Geopolítica feminista não é uma teoria alternativa da geopolítica, mas uma abordagem aos problemas globais com a política feminista em mente" (Tadjbakhsh, 1965).

${ }^{6}$ Percebe-se que grande parte dos conflitos do período Pós-Guerra fria, anos 90, caracterizam-se por serem de caráter étnico, além disso, os conflitos agora passam a se concentrar dentro das unidades políticas, não mais entre Estados. 
Quando a resolução foi aprovada "Felicity Hill, agora Vice-Presidente da Liga Internacional da Mulher pela Paz e Liberdade, declarou que "o último bastião do pensamento sexista na ONU havia caído" (COCKBURN, 2007 apud FRITZ, 2010, p. 344). Mas, será que esta resolução foi suficiente para acabar com o sexismo de uma forma completa na ONU? Parece que Felcity se mostrou muito otimista quanto à resolução, pois de fato a resolução demonstrou um grande avanço quanto aos Direitos das mulheres, mas será que acaba por aí? Pode se dizer que é muito mais complexo, demonstrando deste modo as limitações da ONU, pois como expresso por Fritz (2010) a resolução é mundial, mas a questão da implementação e monitoramento da resolução diz respeito também aos Estados nacionais e para além diz respeito aos indivíduos que participam destas Organizações Internacionais ou Instituições Nacionais e que podem contribuir para a reprodução de papéis sociais. Dentre as dificuldades da resolução 1325 está que:

0 Conselho (de segurança) não estabeleceu um padrão muito alto. De 2000 a 2006, a RCSNU 1325 foi mencionada em apenas 25,52 por cento das resoluções dirigidas a países específicos (69 de 239). Desde a aprovação da resolução, as entidades internacionais (ONU, União Européia, e outros) têm feito muito pouco para promover a participação das mulheres em processos de mediação. Um estudo de 2005 relatou que, de todas as missões de paz em andamento ou recentemente concluídas, até aquele momento, incluindo as missõ es no Sudão e em Aceh, na Indonésia, somente o caso da Uganda foi mediado por uma mulher, Betty Bigombe. Já em 2007 ela não estava mais diretamente envolvida...As mulheres continuam ausentes como mediadoras, e até mesmo como representantes das Nações Unidas, na maioria dos países atingidos pela guerra... A resolução 1325 está fazendo progresso... no entanto, as mulheres, principalmente aquelas que vivem em zonas de conflitos, ativistas ou não, raramente podem ver, tocar ou sentir este progresso (ANDERLINI, 2007 apud FRITZ, 2010, p. 349).

Partindo do pressuposto que a inserção das mulheres em missões de paz é uma abordagem essencialista de gênero, duas autoras apresentam seus respectivos pontos de vista sobre a ONU, respectivamente, Oliveira Simic e Susan Willett. Para Oliveira Simic (2010 apud REBELO, 2012) a presença de mulheres em missões de paz serve apenas como um estímulo para se coibir:

[...] atos de má conduta perpetrados pelos soldados do sexo masculino. Nesse sentido, o aumento de mulheres reduziria a agressividade e a hipermasculinidade, diminuiria as desigualdades existentes e ajudaria a promover uma agenda mais ampla de integração de gênero (SIMIC, 2010 apud REBELO, 2012, p. 40). 
Sendo que, este propósito apenas reforça o papel social generalizado da mulher como possuidora das características de pacificidade, caridade e acolhimento. Susan Willett (2010, REBEL0, 2012, p. 40) compartilha do mesmo pensamento e acrescenta que as estratégias de integração da mulher feitas pela ONU não produzem mudanças institucionais nem de mudança hierárquica de gênero nas operações de paz, visto que:

\begin{abstract}
A estratégia "Integração de Perspectivas de Gênero", segundo a autora, tem sido aplicada dentro de estruturas de poder existentes, que perpetuam a noção de gênero como sinônimo de mulher. Sendo assim, os papéis das mulheres nos processos de paz continuam a ser idealizados - vítimas - e desvalorizados serviços de apoio. Até o momento, "as mulheres têm sido apenas acomodadas nos espaços altamente masculinizados e militarizados das operações de paz", sem que mudanças profundas sejam observadas. (WILLETT, 2010 apud REBELO, 2012, p. 40).
\end{abstract}

Mesmo com a Conferência das Nações Unidas sobre Mulheres de 1985, apenas no Pós Guerra Fria é que se buscou de forma prática a igualdade de gênero com a busca da inserção das mulheres em Missões de Paz. Esta mudança de postura por parte da ONU se deve a três fatores: o número de intervenções feitas pela ONU no mundo, o caráter das intervenções que passam a ser não só de mediação, mas também de reconstrução dos países afetados e por último a mudança do status da mulher na sociedade. Foi "Em 1995, na IV Conferência Mundial sobre mulheres, que se admitiu explicitamente a importância da inclusão feminina nos processos de construção da paz" (MATHIAS, 2010, p. 39). Na Declaração de Pequim adotada pela quarta Conferência Mundial sobre as mulheres: Ação para igualdade, Desenvolvimento e paz 1995, está explícito:

\footnotetext{
A paz local, nacional, regional e global é alcançável e está necessariamente relacionada com os avanços das mulheres, que constituem uma força fundamental para a liderança, a solução de conflitos e a promoção de uma paz duradoura em todos os níveis ${ }^{7}$.
}

Em 2000 esta perspectiva foi adotada então pelo Conselho de Segurança através da resolução 1325 (Mulheres, Paz e Segurança):

\footnotetext{
${ }^{7}$ http://www.dhnet.org.br/direitos/sip/onu/doc/pequim95.htm Acesso em: 14 ago. 2013 
Reafirmando o importante papel das mulheres na prevenção e resolução de conflitos e na construção da paz, e acentuando a importância da sua igual participação e total envolvimento em todos os esforços para a manutenção e promoção da paz e da segurança, bem como a necessidade de aumentar o seu papel na tomada de decisões no que respeita à prevenção e resolução de conflitos ${ }^{8}$.

Mas em 2008 em relatório do Secretário-Geral da ONU, analisa-se que os problemas continuam persistentes:

\begin{abstract}
Apesar dos repetidos apelos do Conselho de Segurança pelo respeito à igualdade de direitos das mulheres e pelo seu papel nos processos de construção e manutenção da paz, milhões de mulheres e crianças ainda representam a maioria das baixas em conflitos, muitas vezes em flagrante violação dos direitos humanos e do direito humanitário internacional. Em conflitos armados e situações pós-conflito, as mulheres são as mais prejudicadas pelo colapso da economia e das estruturas sociais[...].o uso direcionado da violência sexual torna-se cada vez mais uma potente arma de guerra e um fator na desestabilização de sociedades em conflito e pós-conflito (FRITZ, 2010).
\end{abstract}

Para além do que afirma o artigo 8 da Carta das Nações Unidas de que "As Nações Unidas não farão restrições quanto ao acesso de homens e mulheres, em condições de igualdade, a qualquer função nos seus órgãos principais e subordinados", é necessário que as relações de gênero se tornem uma questão sensível aos Estados, para que assim haja um monitoramento das missões de paz referentes as preocupações de gênero, como os abusos 9 . Para Tiago Duque (2008), somente quando a sexualidade deixa de ser entendida como um dado natural e passa a ser compreendida como uma questão social pelas ciências sociais é que ela pode participar da discussão dos Direitos Humanos. Para o autor:

A sexualidade e o gênero são uma das formas mais poderosas de diferenciação social, vetor de formas diversas de desigualdade, daí a necessidade de refletir sobre elas dentro do conjunto de direitos civis, políticos, econômicos, culturais e sociais, considerados fundamentais e universais pela ONU (DUQUE, 2008, p. 1).

\footnotetext{
8 http://www.peacewomen.org/assets/file/TranslationInitiative/1325/1325portuguese.pdf Acesso em: 14 ago. 2013.

${ }^{9}$ Quanto aos abusos "Durante muito tempo, os porta-vozes da ONU justificaram a ocorrência de tais atos como eventos pontuais, inerentes ao comportamento masculino" (REBELO, 2013, p. 829).

Conjuntura Global, Vol. 4, n. 2, maio/ago., 2015, p. 171-184. 
Para Nadine Peuchguirbal (2012) a reprodução de estereótipos essencialistas de gênero presentes nos documentos oficiais da ONU referentes a mulher permite que os tomadores de decisão do sexo masculino as mantenha em posição de subordinadas. Quem também compartilha desta visão é Rita Santos (2012) que compreende a perspectiva de mainstream de gênero e o conceito de gênero na ONU como um discurso neutralizante e que foca na vitimização a mulher. Por meio disto a ONU cria:

[...] versões estereotipadas da feminilidade, que associam as mulheres à passividade, vitimização e construção da paz, a par com modelos estereotipados de masculinidade (violenta, racional e independente) que norteiam os entendimentos e as estratégias de inclusão das perspectivas de gênero no contexto das missões de manutenção de paz [...] Em resultado disso, os papéis de gênero tradicionais são reforçados e as variações entre/dentro das masculinidades e feminilidades são eliminadas (SANTOS, 2012, p. 136).

Deste modo, Peuchguirbal (2012) compreende o essencialismo como uma força política perigosa que fixa identidades por meio de estereótipos para sustentar dominações. Para além disso, "The stereotyping of women appears to be used to keep them away from the peace negotiation table on the grounds that they did not participate in the fighting"10 (PEUCHGUIRBAL, 2012, p. 177). Para Willett (2010) a relação entre homens e mulheres se baseiam nas suposições essencialistas sobre os papéis "naturais" dos sexos, no qual o essencialismo se pauta em estereótipos de gênero tidas como fixas como modo de reforçar as diferenças e desigualdades. 0 essencialismo coloca as características binárias entre os sexos como sendo imutáveis e naturais, sendo assim o homem é o forte, o poderoso e o autoritário e as mulheres as fracas, vulneráveis e passivas.

Quadro 1: Estereótipos das Mulheres nas Missões de Paz

\begin{tabular}{|c|c|}
\hline Mulher & Homem \\
\hline Fraca & Forte \\
\hline Vítima & Protetor \\
\hline Emotiva & Controlado \\
\hline Pacífica & Agressivo \\
\hline Conciliadora & Racional \\
\hline
\end{tabular}

Fonte: Própria autora.

10 Tradução Livre: A esteriotipificação das mulheres parece ser usada para mantê-las longe da mesa de negociação de paz com o argumento de que eles não participaram nos combates.

Conjuntura Global, Vol. 4, n. 2, maio/ago., 2015, p. 171-184. 
A crítica às estas estratégias de equilíbrio de gênero da ONU é de que estas se baseiam na "[...] reafirmação de estereótipos em relação à mulher e ao homem. No caso do gênero feminino, parte--se de uma visão essencialista, que predispõe a figura da mulher em categorias como "mulher-vítima", "mulher-pacifista" e "mulher conciliadora" (REBELO, 2012, p. 79).

\section{A questão de gênero nas Instituições Militares}

Para Orna Sasson-Levy (2011), o militarismo é a instituição mais próxima do essencialismo e de concepções hierárquicas de gênero, bem como concepções especificas de homens e masculinidades, sendo que o problema de gênero perpassa diversos níveis dentro de uma organização como a estrutura, a cultura e a interação.

Deste modo, há muitos impasses ao ingresso da mulher nas forças armadas, como a exclusão das funções relacionadas ao combate, baixa representatividade em posições de poder e a problemática do campus militar que se apresenta à mulher com hostilidade, no qual as mulheres são representações da "discriminação cultural e da segregação ocupacional" (CARREIRAS, 2009, p. 170). Segundo a autora, a esteriotipificação de gênero é que delega à mulher o caráter de feminilidade e paz e aos homens de masculinidade e guerra ${ }^{11}$, sendo estes um dos principais motivos segundo o qual as mulheres não adquirem o caráter de combatente nas Forças Armadas. Mas atualmente se percebe:

[...] notável a ascensão de algumas figuras femininas a cargos antes ocupados unicamente por homens, em espaços tradicionalmente masculinos. 0 desempenho delas uma vez em situações de relativo poder é igualmente relevante. Contrariando estereótipos de gênero enraizados no entendimento popular, algumas mulheres se destacam pela brutalidade e desafiam noções convencionais sobre a relação entre violência e gênero masculino e sobre o que é ser mulher (REBELO, 2012 p. 54).

Propondo uma visão diferente do ingresso das mulheres nas Forças Armadas, Carreiras (2009) utiliza-se do "olhar" masculino para explicar a construção da

\footnotetext{
${ }^{11}$ Muitas vezes devido à construção social de gênero que legitima o status quo do dominante, aspectos culturais são tomados como naturais, o que perpetua visões negativas de gênero durante e ao longo dos anos, ou seja, há uma valorização do corpo masculino, bem como das suas atividades. 
masculinidade nas forças militares. A autora explica que é somente a partir dos anos 70 que grande parte dos países do ocidente aderiu ao ingresso das mulheres às forças armadas, pois é quando começa a surgir relativa igualdade feminina frente aos seus pares masculinos ${ }^{12}$.

No ambiente militar, as mulheres são representações da "discriminação cultural e da segregação ocupacional" (CARREIRAS, 2009, p. 170). Sendo que, a estereotipificação de gênero que delega à mulher o caráter de feminilidade e paz e aos homens de masculinidade de guerra ${ }^{13}$, são um dos principais motivos segundo o qual as mulheres não adquirem o caráter de combatente nas forças armadas. Além disso, as mulheres ainda se defrontam com o problema institucional das forças armadas que tem segundo Carreiras (2009) caráter burocratizante, de centralização política, formal, autoritária e representante das relações dominantes de gênero, no qual se sustentam a masculinidade hegemônica.

Em um estudo etnográfico realizado em quartéis, Silva (2008) revela que o "Ser mulher" se sobrepõe ao fato de "ser militar", no sentido de que a militar ser parecida com um homem, aproxima-a da realidade militar para muitos dos cadetes por ela entrevistados. Sobre a questão de desigualdade, apesar do avanço dos movimentos feministas e da democratização em prol da igualdade de gênero "essa realidade ainda varia quanto ao seu alcance, durabilidade e impactos na cultura política masculinizante" (BOBEA, 2010, p. 118). Sendo que a questão da busca por igualdade não deve ser apenas normativa e legal, ela deve permear as "praticas culturais que se institucionalizaram e que ainda permeiam os paradigmas de reformas" (BOBEA, 2010, p. 147). Quanto às políticas de integração militar femininas, Carreiras (2009), analisa as respostas masculinas a este caso, seguindo a lógica da tabela a seguir:

\footnotetext{
${ }^{12}$ Relativa a tabela 3, sobre o ingresso da mulher nas Forças Armadas.

13Muitas vezes devido à construção social de gênero que legitima o status quo do dominante, aspectos culturais são tomados como naturais, o que perpetua visões negativas de gênero durante e ao longo dos anos, ou seja, há uma valorização do corpo masculino, bem como das suas atividades. 


\section{Figura 1}

Quadro 1 - Tipologia de reações masculinas à presença feminina nas Força Armadas

\begin{tabular}{|c|c|c|c|}
\hline \multirow{3}{*}{$\begin{array}{c}\text { Percepção das } \\
\text { diferenças de gênero }\end{array}$} & \multicolumn{3}{|c|}{ Atitude relativa à aceitação feminina } \\
\hline & \multirow[t]{2}{*}{ Oposição } & \multicolumn{2}{|l|}{ Aceitação } \\
\hline & & Total & Condicional \\
\hline \multirow{2}{*}{$\begin{array}{c}\text { Diferença } \\
\text { (subordinação da mulher) }\end{array}$} & \multirow{2}{*}{ Sexista } & \multirow{2}{*}{-} & Machista \\
\hline & & & Pragmatista \\
\hline $\begin{array}{c}\text { Diferença } \\
\text { (sublimação da mulher) }\end{array}$ & Tradicionalista & - & Cavalheiro \\
\hline Igualdade & [antimilitarista] & Integracionista & - \\
\hline
\end{tabular}

Fonte: Adaptado de Battistelli, 1997.

Fonte: (CARREIRAS, 2009, p. 178).

A explicação a seguir, tem como objetivo exemplificar melhor cada tipologia das reações masculinas acerca da presença feminina nas forças armadas de acordo com (CARREIRAS, 2009). O sexista é aquele que acentua as diferenças entre homens e mulheres e posiciona-se contra a inserção feminina nas forças armadas. Para o sexista, este ingresso tem conotação negativa para a organização militar. 0 tradicionalista também faz distinção entre os homens e as mulheres, bem como o sexista, porém a sua justificativa é de sublimação do caráter feminino. Este perfil idealiza a concepção de mulher. 0 pragmatista também se assemelha as duas visões anteriores, mas a sua justificativa para o não ingresso das mulheres nas forças armadas é pautada nas questões de fragilidades físicas e emocionais das mulheres, porém sua visão sobre o ingresso condicional das mulheres é indiferente.

Já o machista seria aquele que salienta a inferioridade feminina, mas se coloca a favor de uma integração condicional contado que ela não exerça o mesmo papel que os homens, sendo assim o papel das mulheres nas forças armadas seriam administrativo, de apoio e de logística. 0 integralista identifica-se como aquele que se posiciona a favor da igualdade entre os sexos e que reconhece que há problemas no ingresso da mulher, mas que se deve procurar resolver estes problemas. Sendo assim sua visão só ingresso 
das mulheres nas forças armadas é positiva. O cavalheiro é aquele que muito se assemelha ao tradicionalista na questão da sublimação da mulher, mas se diferencia de tal no sentido que se posiciona a favor da entrada das mulheres nas forças armas mesmo que somente em funções de apoio.

Quanto às qualidades femininas que mais são valorizadas pelas forças armadas estão, “o nível elevado de organização; sensibilidade social; distanciamento; de estruturas hierárquicas e protocoladores; inspiração de confiança diante de pessoas do mesmo sexo; flexibilidade; capacidade intuitiva" (ESCOBAR, 2009, p. 58). Estas características têm sido destacadas em missões de manutenção de paz no qual a mulher apresenta um papel de destaque, pois "reconhece-se que as mulheres não necessitam ser protegidas, mas que podem ser também combatentes, prisioneiras, diplomatas ou negociadoras" (ESCOBAR, 2010, p. 58).

\section{Considerações Finais}

O Pós-Guerra Fria traz mudanças importantes para o cenário internacional como a emergência de novos atores e novas temáticas para as Relações Internacionais. Uma destas mudanças ocorre no conceito tradicional de segurança que passa a integrar ações não militarizadas para solução de conflitos, as chamadas missões de paz. Podemos notar alguns avanços quanto a inserção de mulheres em cargos, até então masculinos, como o caso da primeira nomeação de uma mulher ao cargo de chefe de missão da paz da ONU, Kristin Lund de 34 anos que possuía experiência nas Forças Armadas da Noruega, bem como nas Forças da ONU no ano de 2014.

Ao longo da pesquisa alguns pontos importantes são ressaltados como o processo do essencialismo visto como um processo político, pois se pressupõe que um discurso nunca é isento de um significado político, desta forma o essencialismo nada mais é do que um arquétipo de controle, por meio da criação de estereótipos. No caso da ONU, há a naturalização e a reprodução dos estereótipos a partir das suas práticas de missões de paz. Esta diferenciação presente na ONU entre homens e mulheres que parte do essencialismo e cria estereótipos, gera uma "institucionalização" dos papéis sociais, ao passo que dificulta cada vez mais a inserção de mulheres em esferas de tomada de decisão ou quais quer que desejem, já que as mulheres não são um grupo homogêneo. 
É neste ponto que surge a importância do papel da ONU como uma Organização Internacional que legitimada por Estados têm papel central no processo de construção e legitimação dos Direitos dos sexos, devido a sua capacidade de inserir a questão de gênero na agenda política internacional. A importância de organizações internacionais, neste caso, da ONU, nas relações internacionais ao nível sistêmico, ocorre principalmente por conta da interdependência dos Estados, no qual questões globais se entrelaçam criando deste modo, temas da agenda internacional, como no caso das políticas de igualdade para mulheres.

Quanto à questão militar, a partir do que foi apontado percebe-se que a questão de gênero é uma construção social histórica e que para se entender a inserção das mulheres nas Instituições militares é necessário entender como a sociedade é politicamente organizada a partir da perspectiva de gênero. A mulher militar contemporânea está localizada dentro de uma esfera de tempo e espaço que estão para além dela, como as questões culturas, sociopolíticas e a esfera militar em si.

\section{REFERÊNCIAS}

BOBEA, Lilian. Gênero, forças armadas e missões de paz no Caribe. In: Mathias, Suzeley Kalil. (Org.). Sob o signo de Atena: gênero na diplomacia e nas Forças Armadas. São Paulo: UNESP, 2010, v , p. 107-150.

BUZAN, Barry e HANSEN, Lene. A evolução dos estudos de segurança internacional. São Paulo: Editora da UNESP, 2012, Cap. 7

CARREIRAS, Helena (2010). 0 olhar dos homens: resistência e cumplicidade nas respostas masculinas à integração de mulheres nas Forças Armadas. In Suzeley Kalil Mathias e Hector Saint-Pierre (orgs),Mulheres: Defesa e Diplomacia, São Paulo, Ed UNESP.

COSTA, Juliana A. da; SELIS, Lara M. R.; SOARES, Samuel A. De Afrodite à Melíade? o Feminismo nos Estudos de Segurança. In: MATHIAS, Suzeley K. (Org). Sob o signo de Atena: Gênero na diplomacia e nas forças armadas, São Paulo: Editora Unesp, 2009. p.205-228.

D'ARAUJO, Maria Celina Soares . Mulheres, homossexuais e Forças Armadas no Brasil. In: Celso Castro, Victor Izecksohn e Hendrik Kraay. (Org.). Nova história militar do Brasil. 1ed.Rio de Janeiro: Editora da FGV, 2004, v. 1, p. 439-459. 
DUQUE, Tiago. Sexualidade, Abjeção e Direitos Humanos: a experiência GLBTT no Brasil atual. In: 32ํㅡㄹ Encontro Anual da ANPOCS - Associação Nacional de PósGraduação e Pesquisa em Ciências Sociais. 2008, Caxambú/MG. Site Oficial. São Paulo: Zeta Studio, 2008.

ESCOBAR, Loreta Tellería. Mulher, forças armadas e missões de paz na região na região andina.. In: Mathias, Suzeley Kalil. (Org.). Sob o signo de Atena: gênero na diplomacia e nas Forças Armadas. Sao Paulo: UNESP, 2010, v. , p. 51-80.

FRITZ, Jan Marie. Mulheres, Resolução do Conselho de Segurança das Nações Unidas 1325 e a necessidade de planos nacionais. Sociologias [online]. 2010, n.23, pp. 340-353. ISSN 1517-4522.

IZZO, Roberta Cristina. Igualdade de gênero: um caminho para a paz. In: MATHIAS, Suzeley K. (Org). Sob o signo de Atena: Gênero na diplomacia e nas forças armadas, São Paulo: Editora Unesp, 2009. p.205-228.

PUECHGUIRBAL, Nadine. Discourses on Gender, Patriarchy and Resolution 1325: A Textual Analysis of UN Documents. International Peacekeeping. 2010. P. 72-87.

REBELO, T. R. . Lentes de gênero para as missões de paz : desconstrução de discursos e reflexões sobre práticas generificadas. 1. ed. São Paulo: Cultura Acadêmica, 2012. 160p .

SANTOS, Rita. Gênero (masculinidades e feminilidades) e operações de manutenção de paz. NASSER, R. M. (Org.) . O Silêncio das Missões de Paz. 1a. ed. São Paulo: Editora da Pontifícia Universidade Católica de São Paulo, 2012. v. 1. 250p .

SASSON-LEVY, Orna. The Military in a Globalized Environment: Perpetuating an 'Extremely Gendered' Organization. In: JEANES, Emma. Handbook of gender, work, and organization.- Chichester, West Sussex : Wiley, ISBN 9781444394726. - 2011.

SILVA, Cristina Rodrigues. Gênero, Hierarquia e Forças Armadas: um estudo etnográfico acerca da presença de mulheres nos quartéis. Prêmio Lévi-Strauss 2008 Modalidade B. Associação Brasileira de Antropologia, 2008. Disponível em <http://www.abant.org.br/conteudo/000NOTICIAS/Premios/LeviStrauss/cristina.pdf> . Acesso em 19 de set. de 2013.

TADJBAKHSH, Shahrbanou. Human security: concepts and implications / Shahrbanou Tadjbakhsh and Anuradha Chenoy. 1965.

WILLETT., Susan. Introduction: Security Council Resolution 1325: Assessing the Impact on Women, Peace and Security.international Peacekeeping. 2010. p. 142-158. 